\title{
PEM Yakıt Pili Bipolar Plakalarının Geleneksel ve Yenilikçi Üretim Teknikleri
}

\author{
${ }^{1}$ Merve Topcu, ${ }^{* 2}$ Alparslan Topcu, ${ }^{3}$ Kadir Aydın, ${ }^{4}$ Selahattin Çelik, ${ }^{5}$ Nuri Furkan Koçak \\ ${ }^{1}$ Teknik Bilimler Meslek Yüksekokulu, Mülkiyet Koruma ve Güvenlik Bölümü, Harran Üniversitesi, Türkiye \\ ${ }^{* 2}$ Mühendislik Fakültesi, Makine Mühendisliği Bölümü, Adana Alparslan Türkeş Bilim ve Teknoloji Üniversitesi, \\ Türkiye \\ ${ }^{3}$ Mühendislik Fakültesi, Makine Mühendisliği Bölümü, Çukurova Üniversitesi, Türkiye \\ ${ }^{4}$ Mühendislik Fakültesi, Makine Mühendisliği Bölümü, Niğde Ömer Halisdemir Üniversitesi, Türkiye \\ ${ }^{5}$ Nallıhan Meslek Yüksekokulu, Elektronik ve Otomasyon Bölümü, Ankara Üniversitesi, Türkiye
}

\section{Özet}

Yakın gelecekte petrol rezervlerinin tükeneceği öngörülmemektedir, fakat hidrokarbon kökenli yakıtların kullanılması canlılar için sağlığa olumsuz etki eden emisyonlar oluşturmaktadır. Bu nedenle dünya genelinde yenilenebilir, alternatif ve temiz enerji kaynaklarına yönelim söz konusu olmaktadır. Yakıt pilleri, sessiz ve verimli çalışabilen, aynı zamanda zararlı emisyonları olmayan bir elektrik üretecidir. Ticari uygulamaları da bulunan yakıt pilleri, havacılık, otomotiv, askeri, denizaltı yerel ve mobil uygulamalarda kullanılabilmektedir. $\mathrm{Bu}$ da kapsamlı bir uygulama alanı olduğunun göstergesidir. Bu çalışmada yakıt pili tiplerinden PEM yakıt pilleri araştırma konusu olarak seçilmiş ve PEM yakıt pili bileşenlerinden bipolar plakaların üretim teknikleri ele alınmıştır. Geleneksel ve yenilikçi üretim tekniklerinin araştırıldığı bu çalışmada, üretim trendinin ne aşamada olduğu tartışılmış ve konunun gelecek perspektifi göz önünde bulundurularak yapılan araştırmalar değerlendirilmiştir.

Anahtar Kelimeler: PEM yakıt pili, bipolar plaka, üretim teknikleri, geleneksel, toz metalürjisi, eklemeli imalat.

\section{Traditional and Innovative Manufacturing Techniques of Bipolar Plates Used in PEM Fuel Cell}

\begin{abstract}
Oil reserves are not predicted to be wasted in the near future, but usage of hydrocarbon based fuels generates harmful emissions which affects the human health negatively. Therefore, there is a tendency towards renewable, alternative and clean energy sources worldwide. Fuel cells are electricity generators that can operate quietly and efficiently, and also without harmful emissions. Fuel cells can be used in aviation, automotive, military, submarine local and mobile applications which are also used in commercial applications. This situation show that comprehensive application fields of PEMFC. In this study, PEM fuel cell was selected as research area which is a type of fuel cell, and manufacturing techniques of bipolar plates investigated, which is a component of PEMFC. Traditional and innovator production techniques were researched and studies were evaluated in the literature considering the future perspective of the subject.
\end{abstract}

Keywords: PEM fuel cell, bipolar plate, manufacturing techniques, traditional, powder metallurgy, additive manufacturing.

*Sorumlu yazar: Alparslan TOPCU Adres: Mühendislik Fakültesi, Makine Mühendisliği Bölümü, Adana Alparslan Türkeş Bilim ve Teknoloji Üniversitesi, 01250, Adana, Türkiye. E-mail adresi: atopcu@atu.edu.tr, Phone: $+903224550000$ 


\section{Giriş}

Dünya nüfusunun sürekli artması ve insanın enerji ihtiyacının sürekli artış halinde olması nedeniyle enerji talebi günden güne artmaktadır [1-2]. Kullanılan petrol türevi hidrokarbon kökenli yakıtlar, günümüzde enerji ihtiyacını karşılamaktadır. Ancak hava kirliliği artışı da bu yakıt türlerinin kullanımı oranında artmaktadır. Hava kirliliğinin artışı, aynı zamanda sera etkisine de etki etmekte ve dünya genelinde ortalama sıcaklık artışlarına sebep olmaktadır. Bu nedenlerle araştırmacılar uzun yıllardır yeni ve temiz enerji arayışları içindedirler. Temiz enerji kaynaklarından günümüzde en fazla göz önünde bulundurulanı hidrojen enerjisidir. Yakıt pilleri, yakıtın kimyasal enerjisini doğrudan elektriğe çeviren, çevreyi kirletici emisyonlar üretmeyen, yüksek verimli elektrokimyasal cihazlardır [3-6]. Yakıt pillerinin keşfi ve araştırılması 1800'lü yıllara dayansa da, zaman içerisinde yeni icat ve keşiflerle birlikte hep arka planda kalmıştır. Tarihsel gelişimine bakılacak olursa 1960 yılında Gemini uzay mekiğinde kullanılan alkali yakıt pili, ilk başarılı uygulama olarak tarihe geçmiştir. Günümüzde ise, başta otomotiv olmak üzere, askeri, yerel, mobil, havacılık gibi sektörlerde uygulama alanlarına sahiptir. En geniş uygulama alanı otomotiv olmakla birlikte, insansız hava araçlarında kullanılması da büyük hızda araştırılmaktadır. Yakıt pilleri genellikle kendi sistemlerinde kullandıkları elektrolit tipine göre isimlendirilirler. Benzer şekilde çalışma sıcaklıklarına göre, kullanıldıkları uygulama alanlarına göre de gruplama yapılmaktadır. Tablo 1'de literatürde yaygın olarak kullanılan yakıt pili tipleri, ortalama çalışma sıcaklıkları, yakıt ve elektrolit tipleri sunulmuştur. Ayrıca tablodaki sütunlar elektriksel verim, kullanım alanları gibi özellikler eklenerek de genişletilebilir. Burada gösterilen yakıt pillerinin haricinde doğrudan etanol yakıt pili (YP), doğrudan borhidrür YP, metal hidrür YP, elektro-galvanik YP, mikrobiyal YP gibi yakıt pilleri çeşitleri de bulunmaktadır. Buradaki çeşitliliği sağlayan en önemli faktör, gün geçtikçe farklı yakıt pili malzemelerinin keşfedilmesi ve uygulama alanına girmesidir.

Tablo 1. Yakıt pillerinin sinıflandırılması

\begin{tabular}{cccc}
\hline Yakıt Pili (YP) Türü & Çalışma Sıcaklı̆̆ı $\left({ }^{\circ} \mathbf{C}\right)$ & Yakıt Tipi & Elektrolit Tipi \\
\hline PEM YP & $40-200$ & $\mathrm{H}_{2}$ & Polimer \\
\hline Alkali YP & $40-200$ & $\mathrm{H}_{2}$ & KOH \\
\hline Doğrudan Metanol YP & $60-130$ & Metanol & Polimer \\
\hline Fosforik Asit YP & 200 & $\mathrm{H}_{2}$ & Fosforik Asit \\
\hline Erimiş Karbonat YP & 650 & $\mathrm{CH}_{4}, \mathrm{H}_{2}, \mathrm{CO}$ & Erimiş Karbonat \\
\hline Katı Oksit YP & $600-1000$ & $\mathrm{CH}_{4}, \mathrm{H}_{2}, \mathrm{CO}$ & Seramik \\
\hline
\end{tabular}

Yakıt pilleri türleri içinde en gelişmiş ve üzerinde en çok araştırma yapılmış olanı şüphesiz proton değişim membran veya polimer elektrolit membran (PEM) olarak adlandırılan PEM yakıt pilleridir. Düşük sıcaklıklarda çalışması ve düşük sıcaklıklarda bile yüksek verime sahip olması kullanışlılığını artırmaktadır [7-8]. Bununla birlikte modüler yapıya sahip olması, sessiz çalışması, akım yoğunluğunun yüksek olması gibi özellikleri de bulunmaktadır. Olumlu özelliklerinin yanında, sisteminde pahalı platin katalizör bulundurması, katot su dengesi probleminin olması gibi temel olumsuzlukları da bulunmaktadır. Günümüz otomotiv sektöründe lider üreticilerden olan Toyota'nın Mirai modeli, Honda'nın Clarity modeli ve Hyundai'nin Tucson FCX modeli ticarileşmiş ve piyasada bulunan yakıt pilli modelleri olarak karşımıza çıkmaktadır. Bu durum yakıt pilinin ticari başarısını kanıtlar niteliktedir. Bununla birlikte yakıt 
pillerinin insansız hava araçlarında kullanılması, batarya kullanımına oranla daha fazla havada kalma süresi sağladığı için, çok önemli bir avantaj olarak değerlendirilmektedir. Yine yan uygulamalardan denizaltında, uzay mekiklerinde, askeri araçlarda güç kaynağı olarak kullanılmaya uygundur. PEM yakıt pili dışında, katı oksit yakıt pilleri de yerel uygulamalarda çok sık karşılaşılan bir yakıt pili türüdür [9]. Yüksek sıcaklıklarda çalışması, farklı yakıtlar kullanılabilmesi, yüksek verimi, kojenerasyona uygunluğu gibi avantajları sayesinde katı oksit yakıt pilleri bilhassa yerel uygulamalar için öne çıkmaktadır [10-12].

Tipik bir PEM yakıt hücresini oluşturan elemanları içten dışa doğru sıralayacak olursak; polimer membran, membranın iki yüzünde bulunan anot ve katot tabakalar, tabakalar üzerinde yer alan katalizörler, (varsa mikro-poroz katman) katalizörlere yakıt ve havanın ulaşmasını sağlayan bipolar plakalar, bipolar plakalardan akımın çekilmesini sağlayan akım toplayıcı plakalar ve tüm sistemi bir bütün içinde tutan nihai (son) plakalardan oluşmaktadır [13-15]. Tekli PEM hücresinin bileşenlerine ait görsel, Şekil 1'de sunulmuştur.

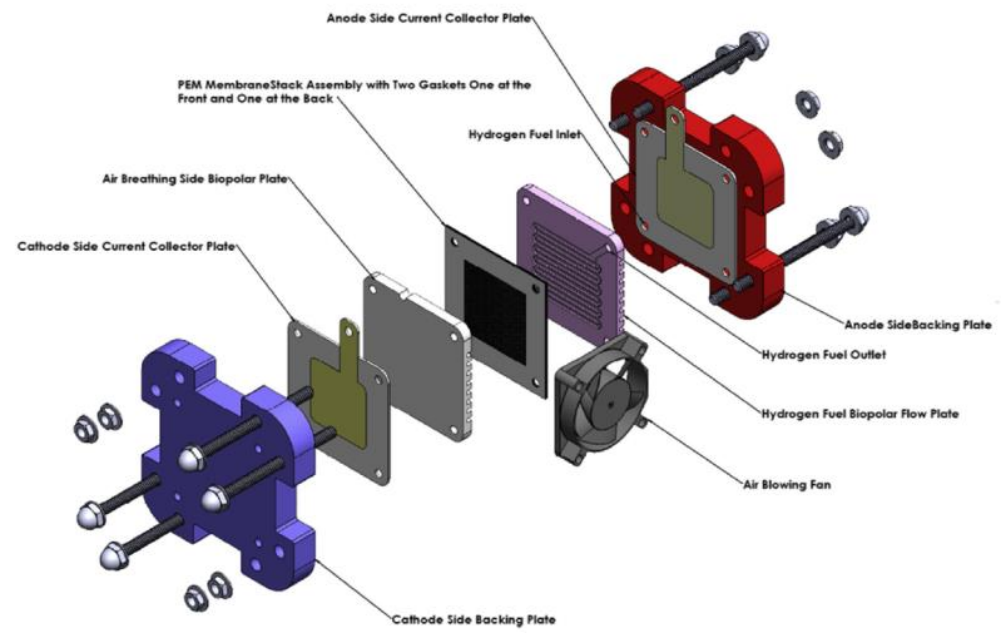

Şekil 1. Tekli PEM hücresinin temel bileşenleri [16]

Bipolar plakaların kanalları vasıtasıyla anot kısmına gönderilen yakıt (hidrojen) katalizör yüzeye (genellikle platin) ulaştığ 1 anda indirgenir, $\mathrm{H}^{+}$iyonlarına dönüşür ve elektronlarını serbest bırakır. Polimer membran; elektronların katot tarafına geçmesine izin vermezken, hidrojen iyonlarının geçişine izin verir. Elektronlar bipolar plakalar üzerinden harici bir akım toplayıcıya doğru akar ve devreden geçerken elektrik akımı elde edilir. Ardından elektronlar katot tarafına ulaştırılır ve burada hidrojen iyonu ve oksijen molekülleriyle birleşerek suyu oluşturur ve sistemi terk eder. PEM yakıt pilinin çalışmasına ait şema Şekil 1'de sunulmuştur.

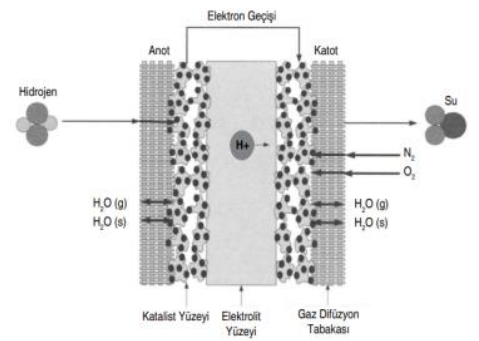

Şekil 2. PEM yakıt pili temel çalışma prensibi [17] 


\section{Bipolar Plakalar}

Bipolar plakalar (BP), yakıt pili sistemi içerisinde önemli bir bileşen olup, reaktant ve oksidant gazların sisteme dağıtılması, reaksiyonlar sonucu oluşan gazların sistemden uzaklaştırılması, elektronların sistemden çekilmesi, stağa mekanik destek sağlama gibi görevleri üstlenir [18-19]. Bipolar plakaların sahip olması gereken özellikleri; yüksek elektriksel iletkenlik, yüksek korozyon direnci, yüksek 1sıl iletkenlik, düşük gaz geçirgenliği, yüksek mukavemet, düşük kontak direnci, hafiflik, düşük maliyettir [15,20-23]. BP’ler stak maliyetinin yaklaşık \%40'ını, stak ağırlığının ise yaklaşık \%80'ini oluşturmaktadırlar [24]. Grafitler, yüksek iletkenliği (oda sıcaklığında $>10^{4} \mathrm{~S} / \mathrm{cm}$ ), korozyon direnci gibi özellikleriyle BP üretimi için en uygun malzemelerdir [25]. Bunun yanında, düşük mukavemeti, kırılganlığı ve yüksek maliyetleri sebebiyle, grafite alternatif olabilecek malzemeler geliştirilmektedir. Grafit dişında metal malzemeler ucuzluk ve erişilebilirlik açısından en uygun malzeme grubudur [26-27]. Paslanmaz çeliklerin dışında bazı kompozit malzemeler de iletkenlik sağlamakta ve paslanmaz çeliklere göre çok daha hafif üretilerek, bir avantaj oluşturmaktadırlar [28]. BP'lerin üretildiği malzemeler gibi üretim metodları da teknolojinin gelişmesiyle değişmekte ve iyileşmektedir. Alt başliklarda üretim metodları ve detaylı sunulmuştur.

\section{Geleneksel Üretim Yöntemleri}

Bipolar plakalar geleneksel olarak talaşlı imalat teknikleriyle üretilmektedir. Dökümden çıkan BP malzemesi talaşlı işlemlere tabi tutularak, akış kanalları ve hava ve yakıt giriş-çıkış kanalları işlenir. Ayrıca yüzeyin pürüzsüzlüğü de sağlanır [29-30]. Geleneksel talaşlı imalat yöntemiyle üretilmiş olan BP'lere örnek Şekil 3'te sunulmuştur.

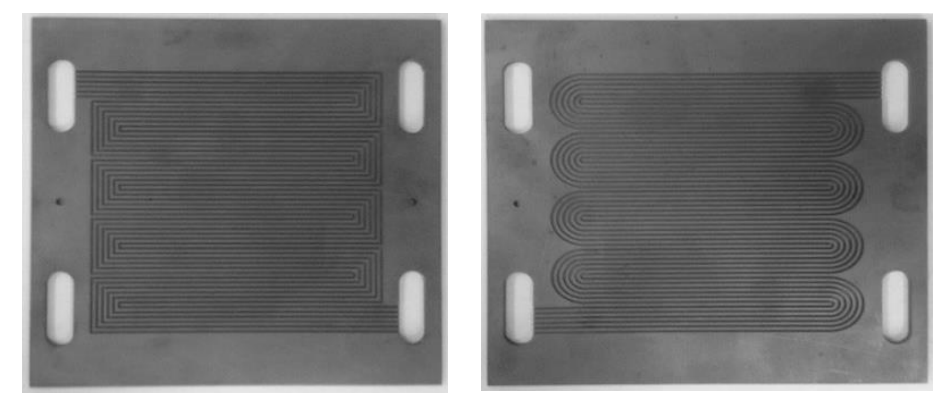

Şekil 3. Talaşlı imalat yöntemiyle üretilmiş BP'lere örnekler [31]

\section{Toz Metalurjisi Yöntemiyle Üretim}

Toz metalürjisi (T/M) çok eski zamanlardan beri kullanılan malzeme üretim tekniğidir. Tozlar boyutları daha önce belli olan bir kalıp içerisine doldurulup, gerekli sıcaklık ve basınç faktörleri göz önünde bulundurulup, sıkıştırılarak istenilen kalınlıkta bir forma kavuşurlar. Daha sonra kalıptan çıkan numuneler belirli sıcaklıklarda sinterlenerek mukavemet kazanırlar. T/M yöntemi ile malzeme üretimine ait bir görsel, Şekil 4'te sunulmuştur. 


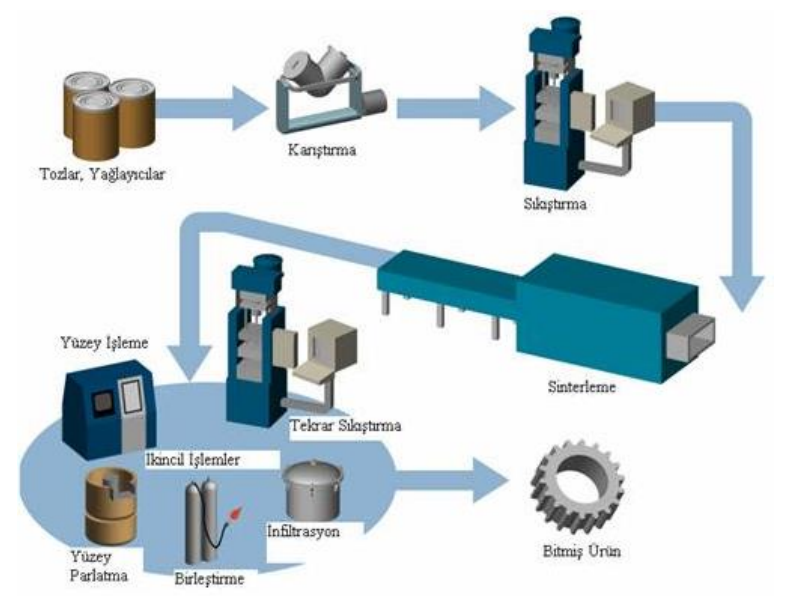

Şekil 4. Toz metalürjisi yöntemiyle malzeme üretimi prosesleri [39]

T/M yöntemi, BP üretimi için de kullanılmaktadır ve geleneksel talaşlı imalat yöntemine göre net şekilli nihai ürün eldesi, hızlı ve yüksek üretim oranı, atık malzemelerin azaltılması veya tamamen bitirilmesi, makine işleme aşamalarının azaltılması gibi üstünlükleri vardır [32]. Włodarczyk vd. toz metalürjisi (T/M) yöntemiyle ürettikleri bipolar plakaların karakterizasyon çalışmalarını yapmışlardır [33-35]. Gerçekleştirdikleri ilk çalışmada T/M yöntemiyle 434LHC ve X20Cr13 ticari isimli tozlardan BP'ler üretmiş ve korozyon davranışlarını incelemişlerdir [33]. İkinci çalışmalarında 304LHD ticari isimli tozu kullanarak T/M yöntemiyle bipolar plaka üretmişler ve 304L kalite paslanmaz çeliğe C-Ni kaplaması uygulayarak, kaplamalı ve kaplamasız BP'ler arasındaki farkları belirlemişlerdir [34]. Diğer bir çalışmalarında ise grafit ve 316LHD tozları kullanarak T/M yöntemiyle BP üretimi gerçekleştirmişler ve elektriksel karakterizasyon çalışması yapmışlardır [35]. Bu ekip haricinde literatüre T/M yöntemiyle yakıt pili BP ve interkonnektörü üretimine katkı sağlayan çalışmalar da bulunmaktadır [21,36-38]. T/M yöntemi ile BP üretiminin avantajları olduğu gibi, dezavantajları da bulunmaktadır.

\section{Kompozit Malzemelerden BP Üretimi}

Kompozit malzemelerden BP üretimi yeni sayılabilecek bir araştırma alanı olup, kompozit malzemeyi oluşturan bileşenlerin çeşitli açılarda üst üste istiflenerek, vakumla veya sıcak pres kullanılarak preslenmesi sonucu elde edilir [40]. Bu şekilde üretilen malzemeler çelikler kadar mukavemetli hale gelebilirken, oldukça hafif olmaktadır. BP olarak kullanılması durumunda ise, kompozit malzemelerden üretilen BP'lerin yüksek elektriksel iletkenliğe sahip olması gerekmektedir. Çünkü BP'lerin en büyük özellikleri yüksek iletken olmalarıdır. Aksi takdirde stak içinde direnç oluşturur ve üretilen elektriğin aktarılmasına engel olarak performans düşüşüne neden olurlar. Bu nedenle literatürde gerçekleştirilen çalışmalar, daha çok elektriksel özelliklerin iyileştirilmesine yönelik olmuştur. Lim ve arkadaşları [41,43] ve Yu vd. [42], karbon fiber/epoksi tabanlı kompozit malzemelerden ürettikleri BP'leri karakterize etmişler ve elektriksel özelliklerini iyileştirmeyi amaçlamışlardır. Barian ve çalışma arkadaşları, karbon nanotüp (CNT) eklentisinin, kompozit BP elektriksel iletkenliğine etkisini araştırmışlardır [43]. CNT eklentisinin artmasıyla elektriksel iletkenliğin arttığını, ancak \%5 katkıdan sonrasında ise, mukavemeti azalttığını belirtmişlerdir. Ayrıca literatürde bulunan diğer çalışmalar da kompozit malzemelerden BP üretilmesi konusunda örnekler teşkil etmektedirler [15,44-47]. Şekil 5 'te Lim 
ve arkadaşlarının üretimini yaptığı karbon fiber tabanlı kompozit BP'lerin üretim şeması gösterilmektedir [47].

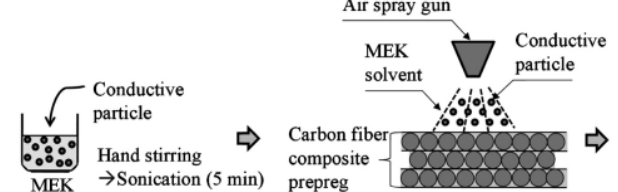

(a)

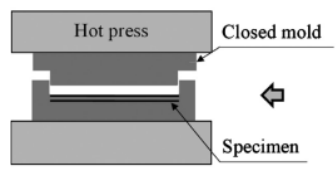

(f) (b)

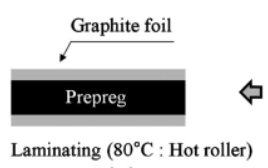

(e)

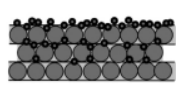

(c)

ㄱ․

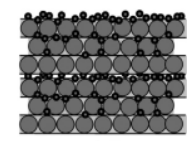

(d)

Şekil 5. Karbon fiber tabanlı kompozit malzeme üretim aşamaları [47]

$\mathrm{Bu}$ şekle bakarak, öncelikle iletken partiküllerin sonikatörde karıştırıldı̆̆ı ve karbon fiber katmanlarının üzerine spreylenerek, karbon fiber malzemenin iletken hale getirilmesi sağlanıyor. $80{ }^{\circ} \mathrm{C}$ 'de tabaka haline getirilen malzeme, sıcak preste preslenerek son halini alıyor. Literatürdeki veriler 1şığında kompozit malzemelerde elektrik iletkenliği probleminin aşılmasında, CNT ve grafen eklentilerinin büyük gelişme kaydedeceği öngörülmektedir [48].

\section{6. Üç Boyutlu Eklemeli İmalat Yöntemiyle Üretim}

Üç boyutlu eklemeli imalat yöntemi, çalışma alanlarımıza son yıllarda yerleşmiş olup, aslında üretim tekniği olarak çok uzun yıllardan beri kullanılmaktadır. Ancak son dönemlerde uygulama alanının genişlemesi, çeşitli malzemelerin üç boyutlu yazıcılarda yazılabilir hale getirilmesiyle daha kapsamlı değerlendirilmektedir. Üç boyutlu eklemeli imalatın en büyük avantajı üretilmek istenen parçanın net şekliyle yazıcıdan üretilerek çıkmasıdır. Dolayısıyla tıpkı T/M yönteminde olduğu gibi üretim sürecindeki talaşlı imalat proseslerinin azaltılmasını veya tamamen yok edilmesini sağlamaktadır. Literatürde yaygın olarak kullanılan eklemeli imalat yöntemi ergiyik biriktirmeli modelleme tekniği (FDM)'dir. Bu metotta en çok kullanılan filamentler ise ABS (akrilonitril butadiyen stiren) ve PLA (poliaktik acid) filamentlerdir. Üretim tekniğinde ise her filamente özgü yazım parametreleri kullanılarak, filamentin yazıcı içerisine çekilmesi sağlanır ve üretilecek parçanın her katmanı ayrı ayrı üst üste eklenir ve her ekleme aşamasında birleştirilerek, önceki katmanla yapışması sağlanır. Ancak bu şekilde üretilen (filamentli) malzemelerin elektriksel iletkenlikleri oldukça düşük olmaktadır. Buna, filamentin içinde bulunan plastikleştirici malzemeler sebep olmaktadır. Bu nedenle PLA ve ABS gibi iletkenliği çok düşük malzemeler, BP olarak kullanılamazlar. Ancak günümüzde grafen katkılı başta olmak üzere çeşitli iletken filamentler geliştirilmesine rağmen, iletkenlikleri henüz istenen düzeyde değildir. Üç boyutlu eklemeli üretim teknikleri yalnızca filamentli yazma teknikleriyle sınırlı değildir. Seçici lazer sinterleme (SLS) ve seçici lazer ergitme (SLM) yöntemleri kullanılarak metal tozları katman katman üst üste serilmekte ve parçayı oluşturan tozlar üst üste serilirken sinterlenmekte veyahut eritilerek üste eklenen tozla birleşmesi sağlanmaktadır. Böylelikle çok mukavim parçalar elde edilebildiği gibi, yoğunlukları da oldukça yüksek olmaktadır. Dolayısıyla bu yöntemle üretilen BP'lerin talaşlı imalat yöntemiyle elde edilen BP özelliklerine yakın olduğunu söylemek 
mümkündür. Literatürde de bu yöntemlerin kullanılmasıyla elde edilen BP'ler mevcuttur [49-51]. Yang vd.'nin yapmış oldukları çalışmada ürettikleri 3D BP'ler Şekil 6'da sunulmuştur [51].

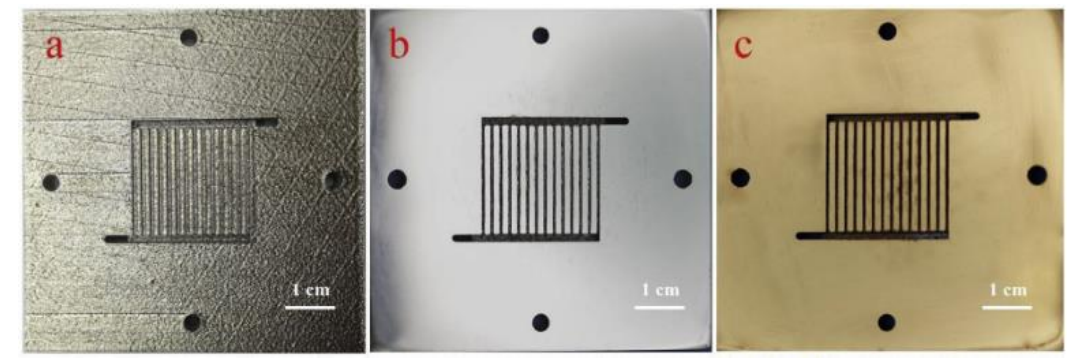

Şekil 6. (a) 3D eklemeli imalatla üretilmiş BP, (b) parlatılmış hali, (c) elektro-kaplamadan sonraki hali [51]

\section{Tartışma}

Yakıt pilleri temiz ve alternatif bir enerji üreteci olup, egzoz gazı olarak yalnızca su ve su buharı (yakıt olarak hidrojen kullanılması durumunda) oluşturmaktadır. Çevreci ve yüksek verimli çalışan bu sistemler, hayatımızda çok geniş bir uygulama alanına sahiptir. PEM yakıt pilleri ise, yakıt pili tiplerinden birisi olup, en gelişmiş ve ticari olarak da piyasada en çok bulunan yakıt pili türüdür. Gerçekleştirilen bu çalışmada, PEM yakıt pillerinde akım toplayıcı ve sisteme gönderilecek gazları dağıtıcı olarak görev yapan bipolar plakaların (BP) geleneksel ve yenilikçi yöntemlerle üretimi araştırılmıştır. Geleneksel olarak talaşlı imalat tekniklerinin kullanıldığı üretim metodunda, dökümden çıkan BP, özellikle CNC-freze tezgahı kullanılarak nihai şeklini almaktadır. $\mathrm{Bu}$ yönteme alternatif olarak literatürde bazı yaklaşımlar da denenmektedir. Kompozit malzemelerden BP üretimi, toz metalürjisi yöntemiyle BP üretimi ve üç boyutlu eklemeli imalatın kullanıldığı yöntemler, alternatif olarak bazı avantajlar ve dezavantajlar sunmaktadır. Hatta bunlarla birlikte stamping ve hidroforming yöntemleriyle BP üretimi de alternatif sayılabilecek yaklaşımlardır. Kompozit malzemelerin hafifliği bir avantajken, elektriksel özelliklerinin zayıf olması, BP olarak kullanım amacından uzaklaştırmaktadır. T/M yöntemiyle üretimde, her ne kadar üretilen BP'ler dens (yoğun) bir yapıda olsa da, gözenekli yapıya sahip olması nedeniyle tane sınırlarında oksidasyon eğilimi oldukça yüksektir. Eklemeli imalat yöntemi son yıllarda üzerinde sıkça durulan bir alan olup, üretilmek istenen BP'nin, üç boyutlu (3D) yazıcıdan olduğu gibi üretilmesi (yüzey düzeltme işlemi hariç) ve hafiflik sağlaması en avantajlı özellikleri olarak öne çıkmaktadır. Ancak filament kullanılarak üretilen 3D BP'ler, plastik katkılı oldukları için, elektirksel özellikleri oldukça zayıf kalmaktadır. Bu nedenle lazer sinterleme ve lazer ergitme metodlarıyla, metal malzemeler kullanılarak üretilen 3D BP'ler, daha avantajlı konumdadır. Zira stak ağırlığının çok büyük bir bölümünü oluşturan BP'lerin, sahip oldukları mekanik ve elektriksel özellikleri yitirmeden, ağırlıklarının azaltılması gerekmektedir.

\section{Kaynaklar}

[1] Ozen DN, Timurkutluk B, Altinisik K. Effects of operation temperature and reactant gas humidity levels on performance of PEM fuel cells. Renew Sust Energ Rev 2016;59:12981306.

[2] Turan C, Cora ÖN, Koç M. Investigation of the effects of process sequence on the contact resistance characteristics of coated metallic bipolar plates for polymer electrolyte 
membrane fuel cells. J Power Sources 2013;243:925-34.

[3] Mahabunphachai S, Cora ÖN, Koç M. Effect of manufacturing processes on formability and surface topography of proton exchange membrane fuel cell metallic bipolar plates. $\mathrm{J}$ Power Sources 2010;195:5269-77.

[4] Turan C, Cora ÖN, Koç M. Contact resistance characteristics of coated metallic bipolar plates for PEM fuel cells - investigations on the effect of manufacturing. Int J Hydrogen Energy 2012;37:18187-204.

[5] Celik S, Timurkutluk B, Mat MD. Measurement of the temperature distribution in a large solid oxide fuel cell short stack. Int J Hydrogen Energy 2013;38:10534-41.

[6] Turan C, Cora ÖN, Koç M. Effect of manufacturing processes on contact resistance characteristics of metallic bipolar plates in PEM fuel cells. Int $\mathbf{J}$ Hydrogen Energy 2011;36:12370-80.

[7] Dur E, Cora ÖN, Koç M. Effect of manufacturing conditions on the corrosion resistance behavior of metallic bipolar plates in proton exchange membrane fuel cells. J Power Sources 2011;196:1235-41.

[8] Peker MF, Cora ÖN, Koç M. Investigations on the variation of corrosion and contact resistance characteristics of metallic bipolar plates manufactured under long-run conditions. Int J Hydrogen Energy 2011;36:15427-36.

[9] Celik S. Influential parameters and performance of a glass-ceramic sealant for solid oxide fuel cells. Ceram Int 2015;41:2744-51.

[10] Canavar M, Mat A, Celik S, Timurkutluk B, Kaplan Y. Investigation of temperature distribution and performance of SOFC short stack with/without machined gas channels. Int J Hydrogen Energy 2016;41:10030-36.

[11] Ertugrul TY, Celik S, Mat MD. Effect of binder burnout on the sealing performance of glass ceramics for solid oxide fuel cells. J Power Sources 2013;242:775-83.

[12] Timurkutluk B, Celik S, Timurkutluk C, Mat MD, Kaplan Y. J Power Sources 2012;213:47-54.

[13] Kahraman H, Orhan MF. Flow field bipolar plates in a proton exchange membrane fuel cell: Analysis \& modeling. Energ Convers Manage 2017;133:363-84.

[14] Dur E, Cora ÖN, Koç M. Experimental investigations on the corrosion resistance characteristics of coated metallic bipolar plates for PEMFC. Int $\mathbf{J}$ Hydrogen Energy 2011;36:7162-73.

[15] Lee HE, Chung YS, Kim SS. Feasibility study on carbon-felt-reinforced thermoplastic composite materials for PEMFC bipolar plates. Compos Struct 2017;180:378-385.

[16] Wilberforce T, El-Hassan Z, Khatib FN, Al Makky A, Mooney J, Barouaji A, Carton JG, Olabi A-G. Development of Bi-polar plate design of PEM fuel cell using CFD techniques. Int J Hydrogen Energy 2017;42:25663-85.

[17] Karaoğlan MU, Kuralay NS. PEM yakıt hücresi modeli. Mühendis ve Makine 2014;55(657):51-58.

[18] Madadi F, Rezaeian A, Edris H, Zhiani M. Improving performance in PEMFC by applying different coatings to metallic bipolar plates. Mater Chem Phys 2019;238:1-10.

[19] Ben Jadi S, El Jaouhari A, Aouzal Z, El Guerraf A, Bouabdallaoui M, Wang R, Bazzaoui EA, Bazzaoui M. Electropolymerization and corrosion resistance of polypyrrole on nickel bipolar plate for PEM fuel cell application. Materials Today, https://doi.org/10.1016/j.matpr.2019.08.072 [Article in Press]. 
[20] Gao P, Xie Z, Wu, X, Ouyang C, Lei T, Yang P, Liu C, Wang J, Ouyang T, Huang Q. Development of Ti bipolar plates with carbon/PTFE/TiN composites coating for PEMFCs. Int J Hydrogen Energy 2018;43:20947-58.

[21] Asri NF, Husaini T, Sulong AB, Majlan EH, Daud WRW. Coating of stainless steel and titanium bipolar plates for anticorrosion in PEMFC: A review. Int J Hydrogen Energy 2017;42:9135-48.

[22] Lee D, Lim JW, Lee DG. Cathode/anode integrated composite bipolar plate for hightemperature PEMFC. Compos Struc 2017;167:144-151.

[23] Mahdavi A, Ranjbar AA, Gorji M, Rahimi-Esbo M. Numerical simulation based design for an innovative PEMFC cooling flow field with metallic bipolar plates. Appl Energy 2018;228:656-66.

[24] Ghorbani MM, Taherian R, Bozorg M. Investigation on physical and electrochemical properties of TiN-coated Monel alloy used for bipolar plates of proton exchange membrane fuel cell. Mater Chem Phy 2019;2381-7.

[25] Wang W-L, He S-M, Lan C-H. Protective graphite coating on metallic bipolar plates for PEMFC applications. Electrochim Acta 2012;62:30-35.

[26] Hou K, Yi P, Peng L, Lai X. Niobium doped amorphous carbon film on metallic bipolar plates for PEMFCs: First principle calculation, microstructure and performance. Int $\mathbf{J}$ Hydrogen Energy 2019;44:3144-56.

[27] Song Y, Zhang C, Ling C-Y, Han M, Yong R-Y, Sun D, Chen J. Review on current research of materials, fabrication and application for bipolar plate in proton exchange membrane fuel cell. Int J Hydrogen Energy, https://doi.org/10.1016/j.ijhydene.2019.07.231 [Article in Press].

[28] Adloo A, Sadeghi M, Masoomi M, Pazhooh HN. High performance polymeric bipolar plate based on polypropylene/graphite/graphene/nano-carbon black composites for PEM fuel cells. Renew Energy 2016;99:867-74

[29] Wu J, Liu X. Recent developments of SOFC metallic interconnect. J Mater Sci Technol 2010;26(4):293-305.

[30] Alcaide F, Cabot P-L, Brillas E. Fuel cells for chemicals and energy cogeneration. J Power Sources 2006;153:47-60.

[31] Youssef ME, Amin RS, El-Khatib KM. Development and performance analysis of PEMFC stack based on bipolar plates fabricated employing different designs. Arab J Chem 2018;11:609-14.

[32] Venskutonis A, Glatz W, Kunschert G. P/M processing of ODS Cr- and FeCr-based alloys for solid oxide fuel cell applications. Prom Electrochem Soc Int Symp SOFC IX. 2005;2:534-44.

[33] Włodarczyk R, Dudek Ai Nitkiewicz Z. Coorosion analysis of sintered material used for low-temperature fuel cell plates. Arch Metall Mater 2011;56(1):181-86.

[34] Włodarczyk R, Zasada D, Morel S, Kacprzak A. A comparison of nickel coated and uncoated sintered stainless steel used as bipolar plates in low-temperature fuel cells. Int J Hydrogen Energy 2016;41:17644-51.

[35] Włodarczyk R. Porous composite for bipolar plate in low emission hydrogen fuel cells. Ecol Eng 2018;19(1):213-20.

[36] Yuan W, Tang Y, Yang X, Wan Z. Porous metal materials for polymer electrolyte 
membrane fuel cells - A review. Appl Energy 2012;94:309-29.

[37] Öztürk B, Topcu A, Cora ÖN, Öztürk S. Oxidation, electrical and mechanical properties of Crofer $^{\circledR} 22$ solid oxide fuel cell metallic interconnects manufactured through powder metallurgy. Int J Hydrogen Energy 2018;43(23):10822-33.

[38] Omrani R, Shabani B. Gas diffusion layer modifications and treatments for improving the performance of proton exchange membrane fuel cells and electrolysers: A review. Int $\mathbf{J}$ Hydrogen Energy 2017;42:28515-36.

[39] Toz metalurjisi nedir? Malzeme nasil üretilir? 2019. http://www.muhendisalemi.com/tozmetalurjisi-nedir-malzeme-nasil-uretilir/. [Accessed 17 September 2019]

[40] Dhakate SR, Sharma S, Borah M, Mathur RB, Dhami TL. Expanded graphite-based electrically conductive composites as bipolar plate for PEM fuel cell. Int J Hydrogen Energy 2008;33:7146-52.

[41] Lim JW, Kim M, Kim KH, Lee DG. Innovative gasketless carbon composite bipolar plates for PEM fuel cells. Int J Hydrogen Energy 2012;37:19018-26.

[42] Yu HN, Lim JW, Kim MK, Lee DG. Plasma treatment of the carbon fiber bipolar plate for PEM fuel cell. Compos Struc 2012;94:1911-18.

[43] Bairan A, Selamat MZ, Sahadan SN, Malingam SD, Mohamad N. Effect of carbon nanotubes loading in multifiller polymer composite as bipolar plate for PEM fuel cell. Procedia Chem 2016;19:91-97.

[44] Husby H, Kongstein OE, Oedegaard A, Seland F. Carbon-polymer composite coatings for PEM fuel cell bipolar plates. Int J Hydrogen Energy 2014;39:951-57.

[45] Lim JW, Lee DG. Carbon composite hybrid bipolar plates with bypass-conducted gas diffusion layers for PEM fuel cells. Compos Struc 2013;95:557-63.

[46] Sisan MM, Sereshki MA, Khorsand H, Siadati MH. Carbon coating for corrosion protection of SS-316L and AA-6061 as bipolar plates of PEM fuel cells. J Alloy Compd 2014;613:288-91.

[47] Lim JW, Kim M, Lee DG. Conductive particles embedded carbon composite bipolar plates for proton exchange membrane fuel cells. Compos Struc 2014;108:757-66.

[48] Taherian R. A review of composite and metallic bipolar plates in proton exchange membrane fuel cell: Materials, fabrication, and material selection. J Power Sources 2014;265:370-90.

[49] Yang G, Mo J, Kang Z, List FA, Green Jr JB, Babu SS, Zhang F-Y. Additive manufactured bipolar plate for high-efficiency hydrogen production in proton exchange membrane electrolyzer cells. Int J Hydrogen Energy 2017;42:14734-40.

[50] Santiago O, Raso MA, Navarro E, Leo TJ. Selection of thermoplastic polymers for use as bipolar plates in direct methanol fuel cell applications. Mater Design 2019;1-14.

[51] Yang G, Yu S, Mo J, Kang Z, Dohrmann Y, List FA, Green Jr JB, Babu SS, Zhang F-Y. Bipolar plate development with additive manufacturing and protective coating for durable and high-efficiency hydrogen production. J Power Sources 2018;396:590-98. 